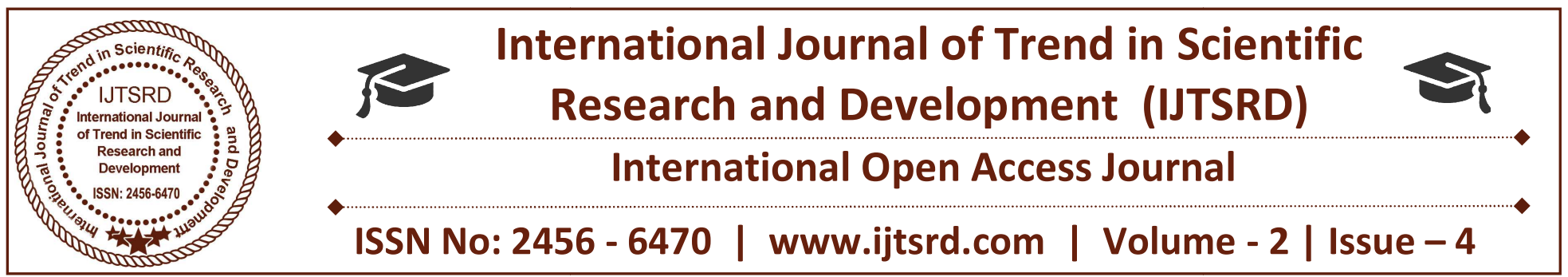

\title{
Exploration of Nano Humidity Sensor in Agriculture Field
}

\author{
Ms. J. Devika, Ms. S. Sasipriya \\ Assistant Professor, Department of Computer Science, KSR Arts and Science College, \\ Thiruchengode, Namakkal, Tamil Nadu, India
}

\section{ABSTRACT}

This paper describes a nano humidity sensor which helps to implement for the growth of plants. Humidity sensors that are used to measure and monitor environmental humidity. A nano humidity sensor which sensors the environment and produces the sensation of soil with the percentage of water that provides a useful plantation for the agriculture plants. The nano humidity sensor, particle embedded with some electronic of motors. Normally nowadays farmers have to maintain the water for plants and they want to cultivate the plants for our country grow Without farmers, no man in the world with basic needs whenever they wants to need cultivation of agriculture is important so only nano humidity sensor is used to maintain the ratios of the soil and so cultivate the plants using nano humidity sensor is easy maintenance for the plant's growth Processor based on embedded soil sensor devices and used with RealTime Operating System for process control on each of these embedded devices and Real Time energy source scheduling, energy source selection, power connection and disconnection are some of the services that are provided to an authenticate farmers in their field.

Keyword: nano technology processor, AT89S52 controller, nano humidity sensor, embedded soil sensors, water percentage.

\section{INTRODUCTION}

To increases agriculture field by using humidity sensors in the soil it gives the timing message when the environment becomes dry. Large number of agri people cant do their agriculture properly due unformal climate condition and no raining climate so they needed to save the water for futhur use mainly for cultivation. Due to unconditional climate they cant give proper growth for plants for that this nano humidity sensor is more using when soil becomes dry it gives the message that soil contain low density of water and is embedded moisture sensor and controller board is used to control the humidity sensors in recent times. Humidity describes the amount of water vapor in the soil. Water vapor is the gaseous state of water and is invisible. A number of ways are available to express humidity, such as absolute humidity, relative humidity, mixing ratio and dew point temperature device used to measure humidity is called a psychrometer or hygrometer.

\subsection{WORKING OF NANO HUMIDITY WITH SOIL MOISTURE SENSOR}

A humidistat is a humidity-triggered switch, often used to control a dehumidifier. Nano humidity is also measured on a global scale using remotely placed satellites .The Soil Moisture sensor uses capacitance to measure dielectric permittivity of the surrounding medium. In soil, dielectric permittivity is a function of the water content. The sensor creates a voltage proportional to the dielectric permittivity, and therefore the water content of the soil. Turn down or off humidifier, and use a dehumidifier when necessary particularly in basements.recent developments in the electrical power area with those in information and communication technologies (ICT) to bring to bear changes to business practices and life styles of farmers. Nano humidity sensor recognizes the distributed nature of electricity industry and the unifying power of the ICT. Traditional way of watering the plants consist of (i) large-scale electricity generators that are located within not reach of energy resources, (ii)high voltage transmission lines but without any knowledge of environments., and (iii) lower voltage distribution networks which in turn 
distribute electrical power to smaller cultivated lands. Unlike such traditional power, nano humidity sensors easily messages the percentage of water in the cultivated lands and have distributed energy generation that encompasses both centrally- located large-scale generators with ratings of 100's of megawatts (MWs) and many geographically.

\section{METHOD:}

2.1 In proposed system nano humidity sensor are dipped aroud the plants to find the percentage of water for the cultivated plants. humidity sensor (or hygrometer) senses, measures and reports the relative humidity in the soil from that maintain our cultivated lands easily. It therefore measures both moisture and soil temperature also. Relative humidity is the ratio of actual moisture in the soil's water content. to the highest amount of moisture that can be held at that soil temperature and check the environmental condition for the cultivation lands .

\section{SYSTEM ARCHITECTURE: \\ 2.1BLOCK DIAGRAM:}

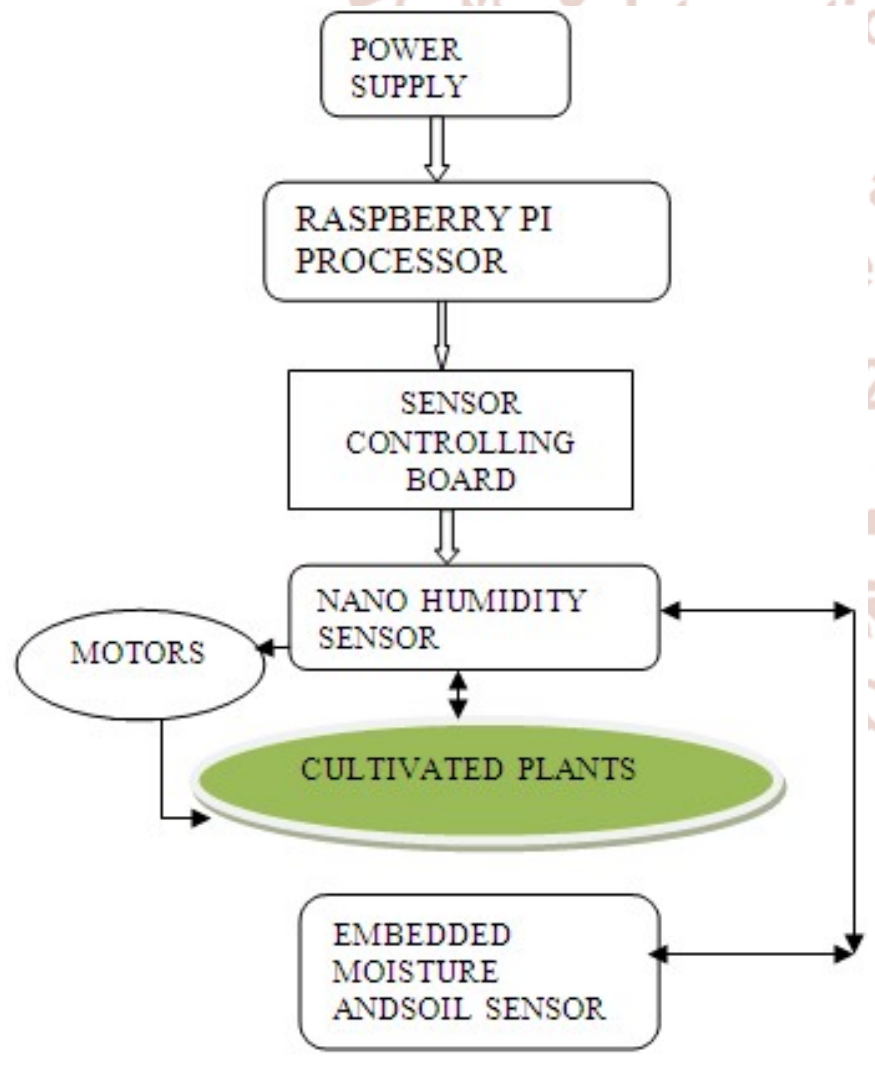

\section{HARDWARE IMPLEMENTATION:}

\subsection{RASPBERRY PI PROCESSOR:}

The Raspberry Pi board contains a processor and graphics chip, program memory (RAM) and various interfaces and connectors for external devices. Some of these devices are essential, others are optional. It operates in the same way as a standard PC, requiring a keyboard for command entry, a display unit and a power supply. The Raspberry Pi board is a miniature marvel, packing considerable computing power into a footprint no larger than accredit card. It's capable of some amazing things, but there are a few things you're going to need to know before you plunge head-first into the bramble patch.

\subsection{AT89S52 CONTROLLER:}

The AT89S52 is a low-power, high-performance CMOS 8-bit microcontroller with $8 \mathrm{~K}$ bytes of insystem programmable Flash memory. The device is manufactured using Atmel's high-density non-volatile memory technology and is compatible with the Industry-standard 80C51 instruction set and pin out. The on- chip Flash allows the program memory to be reprogrammed in-system or by a conventional nonvolatile memory pro-grammar. By combining a versatile 8-bit CPU with in-system programmable Flash on a monolithic chip, the Atmel AT89S52 is a powerful microcontroller which provides a highlyflexible and cost-effective solution to many embedded control applications. The AT89S52 provides the following standard features: $8 \mathrm{~K}$ bytes of Flash, 256 bytes of RAM, 32 I/O lines, Watchdog timer, two data pointers, three 16-bit timer/counters, a six-vector twolevel interrupt architecture, a full duplex serial port, on-chip oscillator, and clock circuitry. In addition, the AT89S52 is designed with static logic for operation down to zero frequency and supports two software selectable power saving modes. The Idle Mode stops the CPU while allowing the RAM, timer/counters, serial port, and interrupt system to continue functioning. The Power-down mode saves the RAM con-tents but freezes the oscillator, disabling all other chip functions until the next interrupt or hardware reset.

\subsection{THE EMBEDDED MOISTURE SENSOR (EMS)}

The EMS sensor is used to perform an indirect measurement of moisture levels in materials not compatible with standard measurement techniques, such as gypsum, concrete, masonry and insulation. The EMS sensor uses known moisture and temperature response curves of Helmlock as a baseline and is further calibrated by correlating the electrical characteristics with gravimetric measurements. Sensors are embedded in the material to be monitored to obtain the relative moisture level of the surrounding area through capillary absorption. 
Sensor readings are acquired by the WiDAQ, a precision data acquisition device, and transmitted to the Building Intelligence Gateway where sensor specific temperature compensated calibration curves are applied. Two sensor grades are available. Commercial grade sensors use published $\mathrm{a}$ and $\mathrm{b}$ calibration values for the wood species used. Research grade sensors are individually calibrated to accurately relate gravimetric moisture content with electrical moisture content. Typical sensor elements are based on Western Hemlock, a hardwood with favourable characteristics.

\subsection{HUMIDITY SENSOR:}

Humidity is a term for the amount of water vapor in the soil, and can refer to any one of several measurements of humidity. Formally, humid soil is not "moist soil" but a mixture of water vapor and other constituents of soil, and humidity is defined in terms of the water content of this mixture, called the Absolute humidity. In everyday usage, it commonly refers to relative humidity, expressed as a percent in weather forecasts and on household humidistat's; it is so called because it measures the current absolute humidity relative to the maximum. Specific humidity is a ratio of the water vapor content of the mixture to the total soil content (on a mass basis). The water vapor content of the mixture can be measured either as mass per volume or as a partial pressure, depending on the usage. the sensor hot enough to function correctly. Connecting five volts at either the A or B pins causes the sensor to emit an analog voltage on the other pins. A resistive load between the output pins and ground sets the sensitivity of the detector. Please note that the picture $i$ the datasheet for the top configuration is wrong. Both configuratio have the ame pin out consistent with the bottom configuration. The resistive load should be calibrated for your particular application using the equations in the datasheet, but a good starting value for the resistor is $20 \mathrm{k} \Omega$.

FIGURE:HUMIDITY SENSOR IN THE SOIL

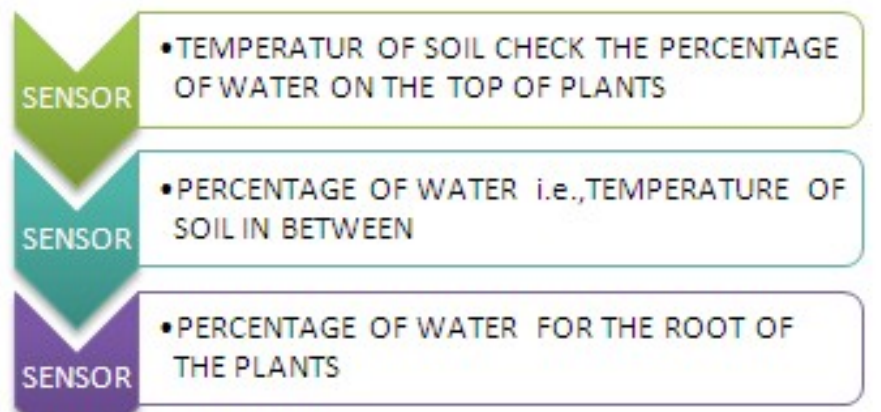

\section{RESULT}

The performance of the humidity sensor was measured by a power supply, a LCR meter, a spectrum analyzer and a test chamber (GTH-099-401P, Giant Force Instruments Enterprise Co.). The test chamber could supply a temperature range of $0-100$ ${ }^{\circ} \mathrm{C}$ and a humidity range of 25-95\% RHTemperature and humidity in the test chamber can be tuned separately and kept at constant levels. The spectrum analyzer was utilized to record the signal response of the sensor to humidity changes. The power supply provided a bias voltage of $3.3 \mathrm{~V}$ to the sensor. In order to characterize the capacitance variation of the sensor to humidity, The test chamber supplied different humidity to the humidity sensor.

\section{CONCLUSION}

The designed system is easy to implement and very customizable according to needs. It provides very effective techniques of using our renewable energy resources which would otherwise have been underutilized. Finally it gives a very effective method for implementing green energy concept on a larger scale The integration of our backgroud agriculture field for growing plants and saving water using nano humidity sensor, agriculture will provide us numerous opportunities for improvements in our energy saving techniques.

\section{REFERENCES}

1. Dhananjay Singh, Gaurav Tripathi, Antonio J. Jara"A survey of Internet-of-Things: Future Vision, Architecture, Challenges and Services" 2014 IEEE World Forum on Internet of Things (WF-IoT) 978-1-4799- 3459-1/14.

2. Saswat Mohanty, Bikash Narayan Panda, Bhavani Shankar Pattnaik "Implementation of Web of Things based Smart Grid to Remotely monitor and control Renewable Energy Sources"2014 IEEE students' conference on Electrical, Electronics and Computer Science.978-1-4799-2526-1/14.

3. ARM. "LPC-2129/2148 Datasheet, "keil.com. [Online]. Available at http://www.keil.com/dd/docs/datashts/philips/lpc2 1xx_ds.pdf[Accessed:Aug.27, 2013].

4. Neoway M660 AT Command Sets data sheet "www.wless.ru/files/gsm/Neoway/Neo_M660_A T_Co mmand_Sets_V1.2.pdf". 
5. Nourai, A., \& Kearns, D. (2010). Batteries included. IEEE Power and Energy Magazine, March, 49-54.

6. Xinghuo, Y., Cecati, C., Dillon, T., \& Simoes, M.G. (2011). The New Frontier of Smart Grids. IEEE Industrial Electronics Magazine, 5(3), 4963.

7. Miyoshi, Y.; Miyajima, K.; Saito, H.; Kudo, H.; Takeuchi, T.; Karube, I.; Mitsubayashi, K. Flexible humidity sensor in a sandwich configuration with a hydrophilic porous membrane. Sens. Actuat. B 2009, 142, 28-32.

8. Li, L.; Vilela, F.; Forgie, J.; Skabara, P.J.; Uttamchandani, D. Miniature humidity microsensor based on organic conductive polymerPoly (3,4-ethylenedioxythiophene). Micro Nano Lett. 2009, 4, 84-87.

9. Juhász, L.; Mizsei, J. Humidity sensor structures with thin film porous alumina for on-chip integration. Thin Solid Film 2009, 517, 61986201.
10. Chen, L.T.; Lee, C.Y.; Cheng, W.H. MEMSbased humidity sensor with integrated temperature compensation mechanism. Sens. Actuat. A. 2008, $147,522-528$.

11. Dai，C.L.; Lu，D.H. Fabrication of a micro humidity sensor with polypyrrole using the CMOS process. In Proceedings of IEEE International Conference on Nano/Micro Engineered and Molecular Systems, Xiamen, China, 2010; pp. 115-118.

12. Hajimiri, A.; Limotyrakis, S.; Lee, T.H. Jitter and phase noise in ring oscillators. IEEE J. Solid-State Circuit. 1999, 34, 790-804.

13. Kang, S.M.; Leblebici, Y. Digital Integrated Circuits; McGraw-Hill: New York, NY, USA, 1996.

14. Geng, L.; Zhao, Y.; Huang, X.; Wang, S.; Zhang, S.; Huang, W.; $\mathrm{Wu}, \mathrm{S}$. The preparation and gas sensitivity study of polypyrrole/zinc oxide. Synth. Metal.

2006 ,

156 ,

1078-1082 